\title{
LOS CORREGIDORES DE LETRAS EN LA ADMINISTRACION TERRITORIAL ANDALUZA DEL SIGLO XVIII
}

\section{Ma Luisa ÁLVAREZ CAÑAS}

Universidad de Alicante

En el conjunto de la Administración territorial andaluza de principios del siglo XVIII la presencia de los corregimientos encomendados a la potestad de jueces letrados, se encontraba en franca minoría frente a las restantes circunscripciones gobernadas por militares y caballeros de capa y espada. En las primeras décadas esta participación se hallaba representada en cinco entidades administrativas, enclavadas en el interior de Andalucía: los corregimientos de Bujalance (Córdoba), Cuatro Villas de la Hoya de Málaga y Vélez-Málaga (Málaga), y Andújar y Quesada (Jaén).

El origen común de estos corregimientos de letras provenía de su segregación de los principales corregimientos de capa y espada andaluces $y$, en principio, la modestia de estos corregimientos se hacía evidente, tanto en la reducida entidad de su superficie territorial, como en la cortedad del vecindario que habitaba en los mismos. Así, en ocasiones, este rasgo característico salía a relucir en las propuestas de letrados elaboradas por la Cámara para cubrir sus vacantes, donde se reconocía el escaso atractivo de ciertos empleos ${ }^{1}$.

No obstante, pese al agravio comparativo que podía pesar sobre estos territorios respecto a los gobernados por caballeros y militares, no todos los destinos cran desdeñables desde el punto de vista del desarrollo particular y del funcionamiento propio de la carrera de letras, sobre todo, si tenemos en cuenta las posibilidades promocionales. Por un lado, se insistía en la peligrosidad que entrañaba el ejercicio de varas en ciertas poblaciones como las pertenecientes a la Hoya de Málaga y Vélez-Málaga, circunstancia que requería sujetos experimentados y de acreditados servicios para asumir la responsabilidad de su mando. Por otro, la designación de hombres para el corregimiento de Bujalance se otorgaba, especialmente a principios de siglo, en calidad de premio y como paso previo a la jubilación en un empleo de cierta entidad política. 
La aparente menor categoría política de los territorios encomendados a la tutela de letrados cambió de signo, cuando las administraciones gobernadas por jueces cobraron transcendencia a raiz de los avances civilistas concedidos a las administraciones territoriales desde las instituciones centrales, con lo que comenzó a destacar la categoría socio-profesional de los hombres que las sirvieron, al tiempo que a partir de mediados del siglo XVIII se multiplicó el número de poblaciones regidas por funcionarios formados en la judicatura.

A las primitivas circunscripciones de letras cuya antigüedad databa de los siglos XVI, en el caso de Quesada y Bujalance, y XVII, en el caso de Andújar, Cuatro Villas de la Hoya de Málaga y Vélez-Málaga, se sumaron por diversas circunstancias los siguientes corregimientos de letras: en 1747 las Siete Villas del Estado de Los Pedroches, por retroventa de la Casa de Alba a la Corona2; en 1754 Utrera, de efímera existencia como tal circunscripción independiente, pues en 1761 su territorio volvió a depender en lo gubernativo de la Asistencia de Sevilla3; en 1760 Estepona, cuya creación se otorgó con el fin de atajar los problemas derivados por la endogamia surgida en la elección de sus autoridades locales ${ }^{4}$; y en 1767 se concedió a la villa de Linares, tras su separación de la tutela de la Intendencia de Minas de Linares.

A partir de estos antecedentes, comenzaron a aplicarse en dichas administraciones de gobierno los fundamentos teórico-prácticos de la política borbónica. El establecimiento de jueces profesionales en sustitución de caballeros y aristócratas se extendió por la transformación de varios corregimientos de capa y espada en corregimientos de letras, así como por el nacimiento de nuevos corregimientos desgajados de la caprichosa distribución territorial heredada, en algunos casos, sin variación desde la época de la Reconquista. Este movimiento de reconversión civilista tuvo sus máximos apoyos el algunos de los principales Tribunales de Justicia, como las Chancillerías de Valladolid y Granada, instancias que se mostraron, por lo general, como defensoras convencidas de un cambio en la dirección político-administrativa. No obstante, como señala el profesor Giménez López:

\begin{abstract}
"Sin embargo, cuando era posible mantener con decoro un corregidor de capa y espada y su alcalde letrado, la Chancillería granadina era partidaria de conservar este tipo de corregimiento e incluso en opinión de su presidente, servirse de ellos como premio a aquellos regidores que se hubieran distinguido en el desempeño de su cargo"6
\end{abstract}

De este modo Carlos III, aconsejado por la Cámara de Castilla, que preveía el lógico ahorro económico de las arcas municipales con la asunción de dos funcionarios en uno, abrió paso a una organización política apoyada en un funcionariado experto en el manejo de las leyes ${ }^{7}$, que sentó las bases de una organización política de marcado carácter civil. Así, a partir de 1767, la Cámara de Castilla planteó al

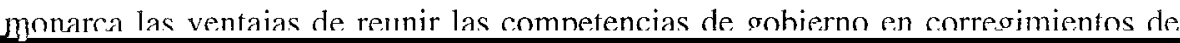


de capa y espada cuyas circunstancias aconsejaran dicha transformación ${ }^{8}$. Aunque este proceso fue ideado para todo el territorio nacional, en Andalucía csa iniciativa sentó precedente con la reconversión en 1768 del corregimiento de capa y espada de Jaén ${ }^{9}$, cuya pauta política fue seguida durante el período $1768-1776$ por la mitad de los corregimientos de capa y espada andaluces. En Ubeda-Baeza se materializó en 1768, con el establecimiento de sendos corregimientos de letras ${ }^{10}$. Al año siguiente se produjo el cambió de rango administrativo de los corregimientos de Carmona y Mancha Real"', y de Guadix y Baza, estos últimos imitando el cjemplo de la modificación administrativa aprobada para Ubeda y Baeza'2. En 1772 tuvo lugar la reforma de la circunscripción de Alcalá la Real, cuyo municipio mantuvo su categoría de capa y espada a costa de la segregación territorial de las alcaldías mayores de Loja y Alhama, que alcanzaron mayor categoría al transformarse en sendos corregimientos de letras ${ }^{13}$. Un poco más tarde, en 1776, también la alcaldía mayor de Marbella obtuvo su independencia de Ronda, y ambas circunscripciones se conformaron en adelante como un corregimiento de letras y uno de capa y espada, respectivamente ${ }^{14}$.

No obstante, a pesar de las realizaciones conseguidas con este proceso en varias circunscripciones andaluzas, así como en el resto de España ${ }^{15}$, no todos los corregimientos llevaron a buén término sus negociaciones para establecer un gobierno civil. Los informes emitidos por las autoridades superiores fueron adversos, sobre todo, por lo que se refiere a gobiernos político-militares como Sanlúcar de Barrameda, Tarifa y Almería que, excepto en el caso de este último ${ }^{16}$, en origen habían sido corregimientos de capa y espada. Unicamente el corregimiento establecido en el Campo de Gibraltar obtuvo la transformación de rango administrativo ${ }^{17}$, con la separación de los poderes militar y político, este último a partir de 1769 en manos de un corregidor letrado. Por el contrario, las fundadas solicitudes de Alcalá la Real, Ecija y Jerez de la Frontera, que se mantenían como corregimientos de capa y espada, no fueron tenidas en cuenta en el desarrollo de la reforma de la administración.

Por otro lado, el visible incremento de corregimientos de letras, a más de motivaciones económicas y políticas, también respondía a la necesidad de racionalizar el entramado administrativo andaluz, caracterizado por los extensos y numerosos territorios comprendidos, hasta estonces, en una única circunscripción. De csle proceso nacieron el corregimiento de las Alpujarras, el de Lucena, y varias alcaldías mayores en otros corregimientos.

\section{Origen socio-profesional de los corregidores letrados}

La procedencia general de los letrados que sirvieron durante el siglo XVIII las varas de gobierno andaluzas se hallaba en ámbitos de modesta categoría social, aunque no exenta, en ocasiones, de cierto lustre sobre todo entre las oligarquías de pequeños municipios. Si bien contituían una minoría, se encuentran algunos ejemplos de letrados cuya extracción se circunscribe entorno a familias de la pequeña nobleza local, tanto rural como urbana. Así lo indicaban las expresiones utilizadas con mayor frecuencia para calificar los orígenes singulares de los caballeros pro- 
puestos para asumir el mando de los corregimientos andaluces: "del estado noble", "de familia noble" y "de noble nacimiento". Esta era la situación de los corregidores de Bujalance Francisco Vicente del Corral (1768-1769), que señalaba su vinculación con ascendientes de distinción, localizados en el reino de Aragón ${ }^{18}$, y de Pablo Antonio Collado Sánchez (1782), que presentaba la prueba de ser descendiente de los primeros pobladores que tras la Reconquista se asentaron en Baza 19. Entre los hombres designados para la vara de Cuatro Villas de la Hoya de Málaga, Francisco Serrano de Frías (1750-1753) era hidalgo en Casarrubios del Monte (Toledo) ${ }^{20}$, y Francisco Agorreta y Nuño (1782-1784) provenía de una familia cuyos miembros eran alcaldes del reino de Navarra21. El corregidor nombrado en Andujar en 1771, Juan Antonio de Santamaría, demostraba que todos sus ascendientes eran hijodalgos o nobles en Molina de Aragón, y él mismo ejerció el cargo de diputado por el estado noble en Madrid desde 178522. La vara de Estepona durante el periodo 1777-1781 estuvo en manos de Antonio Freire de Cora, miembro de una familia noble de Betanzos $^{23}$, mientras que Antonio de la Escalera Gomez y Manzanilla, entre 1781 y 1787 en el mismo cargo, era caballero hijodalgo, regidor perpetuo de Toledo, y desde 1773 se hallaba registrado en el estado noble del padrón de Lucena ${ }^{24}$. En Baza, a partir de 1775 ocupó la vara Antonio de Francia y Urquiola, cuyos parientes nobles se asentaban en Haro (La Rioja), y entre los que destacaba el marqués de San Nicolás, que había sido miembro del Consejo de Hacienda, de quien era sobrino ${ }^{25}$. Los ascendientes de Pedro José de Molina y Muñoz, corregidor de Ubeda (17781782), remontaban la antigüedad de sus méritos personales a su participación en el descubrimiento y reconquista de varias provincias del reino de Perú26. Para acabar, únicamente poseía título nobiliario propio Baltasar de Oñate, corregidor de Jaén entre 1791 y 1797 , bajo la denominación de barón de Oñate.

A pesar de estos ejemplos, el reconocimiento sobre la vinculación familiar a esta categoría de baja nobleza apenas alcanzaba al 6\% (es decir, dieciseis individuos) de los doscientos sesenta y ocho corregidores de letras de Andalucía. Las escuetas referencias en este sentido, solían completarse con variadas informaciones, recogidas en los curricula, que insistían en la marcada continuidad familiar al servicio de la monarquía. Varios letrados demostraban su estrecha relación con ámbitos del gobierno real, a través de los méritos logrados y empleos desempeñados por sus parientes, al mismo tiempo que, alguno de ellos, también se convirtieron en iniciadores de una saga funcionarial a partir de sus descendientes, pues sirvieron de adecuados introductores de sus hijos en las ternas de propuestas para empleos de la administración territorial.

En este aspecto, una de las circunstancias comunes era el contacto establecido tradicionalmente con el mundo castrense. Debido a la relevancia social y al prestigio profesional que entrañaba el estamento militar, constituyó una vertiente digna de mención en los expedientes personales. Ese era el legado de Pedro Moscoso y Figueroa, corregidor de Andujar en 1768, puesto que era hijo del teniente coronel Pedro Moscoso, "oficial de mérito y Honor" y militar de dilatada carrera, que falleció como sargento mayor de la plaza de Cartagena ${ }^{27}$. Del mismo modo, el padre de José García 
de León y Pizarro, corregidor de Baeza entre 1771 y 1775, alcanzó el grado de teniente coronel, y ejerció el mando de distintos gobiernos en las posesiones africanas de la Corona, como las fortalezas de Rosalcázar (1753) y Mazalquivir (1764)28.

No obstante, las alusiones principales con respecto al patrimonio familiar hacían especial hincapié en la tradicional dedicación a la carrera judicial en todas sus vertientes, desde los modestos comienzos al frente de alcaldías mayores de señorío, hasta alcanzar puestos de mayor prestigio en Chancillerías y Audiencias. Así, el corregidor nombrado en 1777 para la circunscripción de Bujalance, Bartolomé Ramos Dávila, hacía constar la trayectoria de su padre en la administración territorial, que había ejercido varios años, y murió en el cargo de auditor de Guerra y Marina del Departamento de Ayamonte ${ }^{29}$. En la misma línea, José Teodosio Delgado y Mentera, destinado en 1770 al corregimiento de Vélez-Málaga, reseñaba un antecedente muy similar, puesto que su padre había desempeñado el cargo de teniente de corregidor de la Coruña y Betanzos (1717), Guadix (1729), Vera (1720) y Baza (1734), y culminó su carrera en Granada, donde murió como teniente de auditor de Guerra ${ }^{30}$.

Este tipo de referencias en algunas oportunidades mostraban historiales profesionales de mayor relevancia, como los señalados por Ventura Antonio Chacón y Mújica y José Guillén de Toledo, corregidores de Andujar en 1733 y en 1800, respectivamente. El primero era hijo de un magistrado que había alcanzado al final de su trayectoria burocrática la plaza de oidor de la Audiencia de Méjico ${ }^{31}$; el segundo era sobrino de Francisco Guillén de Toledo, que había desarrollado una provechosa carrera en la administración territorial, y fue designado en 1769 para una plaza de oidor de la Chancillería de Granada 32.

En general, frente a la insistencia de subrayar la distinción de algunos cxpedientes, la ausencia de datos biográficos sobresalientes, en la mayoría de los curricula de los letrados andaluces, refleja la modestía de los orígenes como característica común, que cra definida con las expresiones "de honrado nacimiento", "de honrada familia", y hasta "de familia honrada labradora y sin oficio mecánico". No obstante, los esfuerzos por adquirir mayor categoría social y, en consecuencia, medrar en la carrera de varas, se plasmaban en el tipo de relaciones familiares establecidas a través de los matrimonios de conveniencia ${ }^{33}$, costumbre que fue también puesta en práctica por los corregidores militares y de capa y espada. Este hecho no pasaba desapercibido en la Cámara de Castilla, según se desprende de los informes cmitidos para la provisión de vacantes. Así se observó respecto a Dionisio Ruiz de Aranda y Carrasquilla, que se había casado con una hija del conscjero de Castilla Luis de Cuellar, conde de la Estrella ${ }^{34}$. Si bien este enlace facilitó su introducción en la administración territorial, sus comienzos fueron modestos. La primera ocasión en que fue propuesto, apareció en la terna de la alcaldía mayor de Fiñana, vara de reciente creación, perteneciente a la jurisdicción del corregimiento de Guadix, y destino descrito como "tan poco apreciable, que dificilmente habrá sujeto de más mérito que la quiera servir" 35 . Aunque por fin no fue designado para la misma, meses después obtuvo la alcaldía mayor de Marbella, una de las de menor entidad. 


\section{Métodos de designación de los corregidores letrados. Estudios universita- rios y preparación práctica.}

A principios del siglo XVIII el procedimiento empleado en la selección del personal destinado a servir las cinco iniciales circunscripciones de letras de Andalucía, obedecía a criterios marcados por los especiales acontecimientos de la época. La cualificación profesional adquirida a través de los estudios universitarios, así como la posterior experiencia práctica eran condiciones inherentes al cargo del corregidor letrado, y en consecuencia, ambos factores determinaban la promoción de los candidatos. Sin embargo, el necesario enunciado de estos requisitos académicos aparecía en ese período velado, y por debajo de otras consideraciones particulares, incluídas en los curricula de los pretendientes.

En la misma línea de gobierno impuesta por el conflicto sucesorio, con la designación de militares en los territorios de la Corona de Aragón, esta influencia marcó su impronta en las circunscripciones andaluzas ${ }^{36}$. Así, prácticamente en todo el litoral del sur peninsular se institucionalizó la presencia de oficiales del ejército en la administración territorial, con la reconversión de los corregimientos situados desde Cádiz a Almería en gobiernos político-militares. De igual forma, se extendió a los corregimientos de capa y espada andaluces, mediante la preferencia de elección de caballeros que demostraron alguna experiencia castrense o eran antiguos oficiales. En principio esta tendencia debía romperse en las demarcaciones de Bujalance, Cuatro Villas de la Hoya de Málaga, Vélez-Málaga, Andujar y Quesada, encomendadas a letrados. No obstante, entre los designados durante el reinado de Felipe V, se observó cierta predilección hacia los que exponían en sus curricula pruebas de poseer un marcado carácter autoritario. Este rasgo era uno de los instrumentos característicos de los hombres al servicio del rey, e implícito al desempeño del cargo de corregidor, cuya capacidad de intimidación, propia del absolutismo, era utilizada sobre todo en el firme control de los pueblos adscritos a la Corona. Así, en los informes elaborados durante los primeros años de la centuria acerca de los caballeros togados, se puso especial énfasis en destacar las intervenciones gubernativas de índole represiva, practicadas con anterioridad por los candidatos con la pretensión, señalada por la Cámara, de que sirvieran de modelo a los integrantes de la carrera de varas. En el año 1714, la elección de corregidor para Bujalance se decantó por Juan Antonio de Torremocha. Además de su experiencia administrativa en otras varas, como las alcaldías mayores de Ubeda, Baeza y Jaén, los miembros de la Cámara de Castilla resaltaron la eficacia del candidato en la captura de un conocido bandido. Esta circunstancia constituyó el factor decisivo para la promoción de Torremocha al empleo, pues según se notificaba, debía ser tomado como ejemplo entre sus compañeros de profesión ${ }^{37}$. La firmeza en el uso de la autoridad, y sus logros represivos en el terreno de la delincuencia, también justificaron la designación de Jerónimo José Carbonel en Cuatro Villas de la Hoya de Málaga, circunscripción que entonces era calificada problemática, por el carácter insurgente de sus pobladores. Las cualidades del candidato, se asentaban en el cumplimiento de comisiones relativas a la persecución de ladrones y gitanos, 
y en las condenas que había impuesto ${ }^{38}$. En ocasiones, este tipo de gestión prevaleció incluso sobre la correcta administración de justicia, como se revela a partir de los contradictorios informes emitidos respecto al mismo sujeto. Por un lado, se elogiaba su capacidad resolutiva en asuntos criminales y, por otro, se le hacía responsable de excesos en la aplicación de sentencias y castigos $^{39}$.

La necesidad de la nueva dinastía de obtener el pleno respaldo del funcionariado, encargado de los territorios circunscritos a la responsabilidad de los letrados, también fue garantizada mediante la recompensa de aquellos pretendientes que se habían distinguido por su lealtad a Felipe V. Este aspecto se hizo evidente en la colocación al frente de los corregimientos de letras de individuos que, además de haberse curtido en el control de gobierno, justificaban su fidelidad a la Corona. En algunos casos se trataba de contribuciones materiales al sostenimiento de la guerra, como las aportaciones realizadas por los licenciados Antonio Cristobal Cornejo y Francisco Cayetano Rodríguez de Santisteban. El primero había entregado cuatro caballos, entre los años 1706 y 1708, con destino a engrosar las caballerizas reales, y consiguió la reunión de otros cuarenta equinos ${ }^{40}$, que fueron ofrecidos a la Corona en forma de donativo. Esta aplicacción a la contienda fue correspondida en 1709, con el cargo de corregidor de Andujar ${ }^{4}$. En otras ocasiones, los méritos de los aspirantes durante el conflicto sucesorio reflejaban colaboraciones de tipo personal. La recomendación que avalaba el trabajo emprendido por Alonso Andrés de León en la alcaldía mayor de Badajoz, se ceñía a su diligencia en el esfuerzo bélico ${ }^{42}$, y le proporcionó su ascenso al corregimiento de Cuatro Villas de Málaga. Sobre Luis Carlos Alvarez, propuesto para el corregimiento de Bujalance en 1718, informaba la Cámara acerca de su difícil trayectoria profesional en Aragón, donde "padeció por buen vasallo en las turbaciones de aquel reino, habiendo sido encarcelado dos veces"43. Pero en definitiva, en el primer tercio de siglo, las características que impusieron su predominio y definieron profesionalmente a la mayoría de los corregidores letrados que obtuvieron plaza en Andalucía, hacían referencia a la experiencia y a la antigüedad adquiridas en la administración territorial; sin embargo, en esta época, los informes apenas mostraban información relativa a la preparación académica. Los múltiples ejemplos que evidencian esta doble circunstancia se encuentran, sobre todo, en la provisión de las vacantes de Bujalance, Cuatro Villas de Málaga, Vélez-Málaga y Andujar, destinos que se convirtieron en lugar ascenso y retiro para letrados longevos, mientras que en Quesada, el relevo de la autoridad fue asignada con mayor frecuencia a principiantes o a letrados de carrera mediocre.

Una vez superada la crisis de los primeros años del siglo XVIII empieza a observarse un cambio cualitativo en el contenido de los datos biográficos relativos a los pretendientes. La información acerca de su preparación universitaria y la calidad del aprovechamiento práctico en el estudio de derecho, cobran mayor protagonismo. En este sentido, el avance civilista producido a finales de 1749 a partir de la designación de los alcaldes mayores a través de consulta a la Cámara de Castilla, influyó decisivamente en la transparencia informativa de la nómina de los abogados que ini- 
ciaban la carrera de varas como tenientes de corregidor. Del mismo modo, el progresivo aumento de las circunscripciones de letras, confirió mayor presencia y peso socio-político a los letrados. En ese proceso de transformación administrativa pasaron a ser mayoría en el conjunto de gobiernos andaluces, pues a lo largo del Siglo XVIII se alcanzó la cifra de veintiuna circunscripciones de letras, frente a siete corregimientos militares y seis de capa y espada ${ }^{44}$.

La riqueza de datos biográficos nos permite establecer el origen geográfico de los letrados que sirvieron en Andalucía, aspecto que sirve de avance para determinar los lugares donde cursaron sus primeros estudios. Así, sobre la procedencia del $51 \%$ de los corregidores de letras (137 individuos) es posible confirmar la mayor presencia de abogados oriundos de las provincias andaluzas (35\%), seguidos en número de los naturales de ambas Castillas y de Madrid (23\%), y a bastante distancia de los murcianos (8\%), el resto de los abogados contabilizados representan cifras poco significativas ${ }^{45}$. Estos resultados coinciden a grandes rasgos con el origen del resto de los corregidores militares y de capa y espada destinados en Andalucía. Entre estos totales únicamente se aprecia una tendencia más constante de los letrados elegidos para los corregimientos más antiguos de Bujalance, Cuatro Villas de la Hoya de Málaga y Vélez-Málaga cuyo nacimiento se situaba en Andalucía.

La distribución geográfica complementa los datos relativos a la formación académica. La mayoría realizó sus estudios de derecho en la Universidad de Granada, seguida por las universidades de Valladolid y Salamanca. También se especifica el paso por otros centros académicos como Alcalá de Henares, Sevilla, Huesca y Zaragoza. Algunos completaban su preparación en más de una universidad, y en muchas ocasiones iniciaban su formación intelectual en centro menores, normalmente cercanos a su lugar de origen, donde solían cursar diversas materias antes de emprender el conocimiento de derecho en ámbitos universitarios superiores, de forma que las muestras de los variados recorridos efectuados por los pretendientes son múltiples.

El grupo de letrados que procedía de Colegios mayores era muy reducido, pues esta condición privilegiada y exclusiva de las élites sociales no se encontraba acorde a la responsabilidad política menor que ofrecía los corregimientos de letras, frente a la mayor categoría de poder que entrañaban las plazas de los tribunales superiores, empleos a los que solían optar con mayor frecuencia ${ }^{46}$. No obstante, los colegiales que entraron al servicio de la administración territorial andaluza alcanzaron el número de quince, es decir, tan sólo un porcentaje del 5,5\% del total de letrados. En definitiva, al igual que ocurría en otras regiones españolas, la pequeña muestra que participó en esas circunscripciones pertenecía sobre todo a los colegios mayores de menor entidad, siendo excepcional la intervención de miembros de los colegios más prestigiosos. Dicho fenómeno constituyó una de las muestras de la pérdida de influencia de este grupo elitista, que fue sustituido de forma mayoritaria por los man- 
teistas, siguiendo los dictados de la política civilista de Manuel de Roda y Pedro Rodriguez Campomanes ${ }^{47}$.

Asímismo fueron escasos los corregidores andaluces que aspiraron y obtuvicron el grado académico de doctor ${ }^{48}$, o que se dedicaron a impartir labores de docencia universitaria. En esta ocasión, el número de doctores consignados apenas superó el 2,5\% del total, y la mayoría procedía de la Corona de Aragón ${ }^{49}$.

La experiencia adquirida a través del paso por la Universidad se convirtió en un requisito prioritario y, en consecuencia, en una garantía para la promoción del personal judicial a puestos de responsabilidad territorial. Además de la capacidad mostrada en el proceso de formación académica, se tuvo en consideración la dedicación a la enseñanza, así como los méritos derivados de los examenes de oposición a que se sometieron algunos de los letrados ${ }^{50}$. En este sentido se distinguieron del resto aquellos abogados que optaron a cátedras y comenzaron su trayectoria profesional en el ámbito académico, impartiendo clases en alguna de las universidades españolas ${ }^{51}$. Estas circunstancias fueron ensalzadas en los informes redactados sobre los pretendientes a varas, y facilitaron a los camaristas la ocasión de emitir los juicios de valor pertinentes a la evaluación de los méritos examinados. Así, Manuel Francisco de Irisarri y Alberro, fue ensalzado por Manuel Arredondo Carmona cuando apareció en la consulta de la vacante del corregimiento de Andujar: " en la Universidad de Valladolid y se había distinguido y adelantado entre los demás prolesores de su tiempo" 52 . En parecidos términos fue considerada la experiencia aportada por Blas Tenorio de Mendoza en el terreno docente, cuando fue propuesto para ocupar el corregimiento de Baeza ${ }^{53}$.

También sobresalía Ventura Antonio Chacón y Mújica, graduado de bachiller en cánones y leyes por la Universidad de Méjico en 1691, se incorporó al año siguiente a la de Salamanca, donde sustituyó la cátedra de Instituta y la de Decreto ${ }^{54}$.

Como complemento obligado, una vez concluidos los estudios universitarios, el paso siguiente y más frecuente consistía en completar los conocimientos teóricos de jurisprudencia mediante el ejercicio práctico forense, a fín de adquirir desenvoltura en la profesión. Normalmente, los nuevos abogados acudían a los bufetes de reconocidos juristas para desempeñar labores de pasantía. Asímismo, procuraban su ingreso en alguna de las academias de derecho que, fundadas a tal efecto, se nutrían de aquellos letrados pretendientes a vacantes en la administración territorial.

Respecto a los magistrados de prestigio que sirvieron de mentores a los recién licenciados se encontraban varios miembros de los principales tribunales de justicia. En conjunto, predominaban los magistrados vinculados a la Chancillería de Granada, instancia judicial más cercana, junto a la Audiencia de Sevilla, a los numerosos abogados de origen andaluz ${ }^{55}$. Por otro lado, los corregidores Ramón Patricio Moreno y Joaquín Antonio Brañas se formaron en la Junta práctica de jurisprudencia presidida por el abogado de la Chancillería de Valladolid Juan López Herreros. Del mismo modo, fueron numerosos los letrados que asistieron a la Real Academia de Santa Bárbara de Madrid ${ }^{56}$, entre los que se contaron los 
corregidores Felix de la Plaza Isasi, Antonio Andrés González y Dionisio Ruíz de Aranda y Carrasquilla. Al parecer la importancia académica de este centro radicaba, sobre todo, en su localización junto a la Corte ${ }^{57}$, lugar al que acudían los abogados bisoños en busqueda de colocación e influencias ${ }^{58}$. Otro de los requisitos previos al desempeño del cargo fue el examen preceptivo en las Chancillerías y Audiencias, y en los Reales Consejos, para su incorporación en alguno de los Colegios profesionales de abogados. De nuevo, en la nómina de letrados que nos ocupa, la mayoría obtuvo primero el reconocimiento oficial del título de abogado por la Chancillería de Granada, seguida por la de Valladolid y la Audiencia de Sevilla, y en menor proporción por la Audiencia de Zaragoza, la de Galicia y un individuo por el Consejo de Navarra.

Antes de conseguir su inclusión en las ternas de propuestas para cubrir vacantes en la administración territorial, los esfuerzos de estos abogados se encaminaban al desempeño profesional de su carrera en otros ámbitos. Por tanto, también fue habitual el ejercicio de la abogacía en los lugares de origen, a partir del establecimiento de un despacho propio, o una vez conseguido el título de abogado de una población o algún otro empleo de índole municipal ${ }^{59}$.

En el primer supuesto, encontramos catorce pretendientes que indicaban su experiencia en un despacho propio, incluso durante largo tiempo, como Antonio Anguiozar y Velasco, que lo mantuvo abierto once años, o en más de una ciudad, como Francisco Serrano de Frías, establecido en Madrid y en Toledo ${ }^{60}$. Otros ejercieron labores administrativas en oficios de carácter municipal y de cierta distinción social como las regidurías, aunque la posesión de este título fue mucho menos frecuente que entre los corregidores de capa y espada, estos caballeros estuvieron considerados como miembros de una nobleza administrativa frente a la modesta procedencia social de la mayoría de los letrados. Así, sólo cinco corregidores de letras declaraban su condición de regidores: Ramón Cid de Araujo era capitular del ayuntamiento de Plasencia (Cáceres) y Antonio José Cortés de Villanueva de la Serena (Badajoz); Gaspar Delgado y Llanos de Medina del Campo (Valladolid) y Juan José de Cañaveras de Huete (Cuenca); Juan Pablo Salvador y Asprer de Villafranca del Penedés (Barcelona); y José Jiménez de Cenarve, de Jaca.

En la calificación del los méritos de los pretendientes también se incluyeron las primeras experiencias laborales en otras jurisdicciones. Algunos señalaron sus comienzos en la práctica del derecho al servicio de la Iglesia: Juan Moreno Vallejo había recibido el encargo de alguacil mayor de la Inquisición de Córdoba en Cazorla, a la sazón, su villa natal61; Pedro Pablo de Pereda opositó al cabildo de la doctoral de la Santa Iglesia de Coria, para el desempeño de sus negocios judiciales, y ejerció la plaza de fiscal eclesiástico del Obispado de Plasencia ${ }^{62}$; y Francisco Serrano de Frías se mantuvo en sus comienzos profesionales como abogado de presos del Santo Oficio de Toledo63.

Otro camino que hizo posible a los letrados la consideración de su idoneidad fue la dedicación en la administración de los intereses patrimoniales de la jurisdic- 
ción señorial. En un análisis comparativo, la habilidad mostrada en distintos ámbitos de gobierno, facilitaba la identificación de los rasgos profesionales y la capacidad política de los aspirantes, dedicados en esa oportunidad a la defensa de los intereses pertenecientes al titular del dominio territorial ${ }^{64}$.

La justificación de experiencia gubernativa por parte de los pretendientes letrados, en el ejercicio de los asuntos y negocios concernientes a la nobleza, fue bastante habitual a lo largo del siglo XVIII. La considerable extensión de los territorios de jurisdicción señorial, sobre todo en la región andaluza, donde permanecían los más antiguos linajes de la aristocracia española, proporcionó la práctica forense a muchos abogados, que emprendieron la carrera político-judicial a partir de los nombramientos otorgados por los principales titulares de esas casas. Bartolomé Ramos Dávila, corregidor de Bujalance en 1777, dedicó dieciocho años de su carrera a la gestión de varas pertenecientes a la Casa de Medinasidonia 65 . El corregidor Antonio Anguiozar y, Velasco fue designado en 1766 por los duques de Osuna y Frías como su representante legal, para hacerse cargo del despacho de los pleitos originados de su casa y estados. Del mismo modo, Manuel Fernando Serrano y Cillero, por nombramiento del duque de Frías, fue el responsable de tomar el juicio de residencia a las autoridades de la villa de Belorado ${ }^{66}$. Alonso López Camacho inició su recorrido profesional como alcalde mayor de Vélez-Blanco, María, Vélez-Rubio, Oria, Partaloba y otros pueblos incluidos en la jurisdicción del marqués de Villafranca, Montalto y Vélez ${ }^{67}$. Asímismo, el servicio en la administración de patrimonios señoriales situados en otras regiones españolas aparecía reflejado en los currícula de los aspirantes. Esas fueron las circunstancias de Antonio Freire de Cora, que se encontró, por designación del duque de Béjar, titular del estado de Lemos, al frente del corregimiento de Monforte de Lemos (Lugo) ${ }^{68}$.

Las primeras colaboraciones de los letrados con el aparato burocrático del gobierno central solían establecerse a partir de comisiones especiales, en las cuales los abogados noveles se encargaban de solucionar problemas puntuales o asuntos de carácter judicial, como respuesta a la demanda de intervención real, en las circunscripciones que así lo requerían. La variedad tipológica de estas gestiones, cuya asunción sólo tenían un carácter eventual, era tan amplia como las funciones conferidas a los hombres de letras, es decir, podía tratarse de asuntos políticos, jurídicos o económicos. Los procedimientos acometidos con mayor frecuencia se centraban en las distintas formas que la monarquía tenía previstas para fiscalizar las labores de gobierno encomendadas a sus autoridades, tales como las pesquisas y, sobre todo, los juicios de residencia. Como método de control de las responsabilidades penales en que incurrían los oficiales de la Corona, la pesquisa era uno de los instrumentos utilizados por la monarquía para investigar el alcance, punible o no, del comportamiento de sus delegados en el municipio ${ }^{69}$. En este apartado, la experiencia adquirida en el desempeño de las principales atribuciones inherentes a los hombres de letras, constituía uno de los mejores terrenos de prueba para adquirir prestigio y sobresalir en el manejo de la administración territorial. La evaluación de responsabilidades a que debían someterse los cargos públicos de la administración territorial, en principio 
correspondía a los corregidores recién nombrados y que tomaban el relevo del saliente. Sin embargo, esta norma se incumplía en la práctica, según advierte el profesor González Alonso:

"La tradición de que el corregidor residencie a su antecesor vuelve a interrumpirse, comisionándose para tomarlas a ministros de las audiencias o chancillerías y a abogados de probada competencia -según la importancia del corregimiento- que reasumen entre tanto el ejercicio del cargo cuyo titular es suspendido por la incoación del juicio"70.

\section{Perfil del ejercicio de gobierno de los corregidores de letras}

El talante perfilado en el comportamiento de los corregidores de letras con respecto a su modo de proceder gubernativo, derivaba en parte de sus orígenes sociales y familiares, pero sobre este aspecto diferenciador con relación al resto de los corregidores militares y de capa y espada, predominaba la formación profesional. La normativa que regulaba la adecuación de los responsables de varas al empleo experimentó una positiva evolución que consiguió dotar a la fígura del corregidor de letras de un carácter más definido de autoridad funcionarial, sujeto a la normativa legal de la burocracia moderna. No obstante, la transformación de los fundamentos teóricoprácticos en que se apoyaba el entramado de la administración territorial fue lenta y difícil en algunos períodos del siglo XVIII, debido a los avatares ministeriales y a las tendencias imperantes en los respectivos gabinetes de la monarquía absoluta ${ }^{71}$.

El pequeño reducto geográfico adscrito al gobierno de los hombres de leyes apenas destacaba, debido a la pequeña entidad territorial y política de las circunscripciones a cllos concedidas. Por fin, durante el reinado de Carlos III fue cuando se emprendieron las reformas administrativas de mayor calado en el sistema corregimental. Con la asunción en 1762 de Pedro Rodriguez Campomanes de la fiscalía civil del Consejo de Castilla, se marcó el inicio de una transformación burocrática inclinada hacia la racionalización de los cargos gubernativos, asignados a civiles profesionales del derecho ${ }^{72}$. La nueva aplicación ministerial, que se convertiría más larde en un método de reglamentación adecuado a las exigencias de la provisión de los corregimientos y alcaldías mayores, por real decreto de 1783, introdujo la transformación del mapa corregimental, y convirtió la gestión de los letrados en el método de gobierno predominante. Las muestras que mejor describen el cambio experimentado en la administración corregimental, se hacen más evidentes en el amplio contexto de los territorios de letras. Las manifestaciones globales que con mayor precisión indican el grado de adaptación, así como la aceptación de las poblaciones al modo de gobierno de los letrados en los municipios andaluces, son las peticiones de prórroga con respecto a los corregidores que ya habían consumido su período en el cargo. Además, este tipo de solicitudes adquieren mayor significado en cl caso de los corregimientos de letras, puesto que era en dichas circunscripciones donde más estrictamente se cumplía el plazo previsto por la normativa vigente para ejercer el 
mando. La duración trienal del cargo, hasta la modificación del reglamento emitido por ley de 1783 que lo prolongaba a un sexenio, generalmente fue observada por la mayor parte de los responsables designados en ese largo período del siglo. Es más, las cifras que contabilizan el número de corregidores que sobrepasaron el trienio y se mantuvieron en la vara en un umbral de 4 a 6 años, corresponden en su mayoría al frecuente fenómeno del retraso encadenado entre la autoridad saliente y la entrante. Así, la entrega de relevo de un mando a otro dilataba la transferencia de responsabilidades en varios meses, de forma que muchos corregidores permanecieron 4 años hasta su sustitución, y solían acceder al siguiente destino también con demora.

La habitual brevedad cronológica en el uso del gobierno preceptivo se reforzaba en el caso de aquellos letrados que, en un número muy elevado de ocasiones, no llegaron a completar los tres años de servicio, y que en concreto alcanzó a cuarenta y seis individuos. Las razones que determinaron estas estancias mínimas al frente de los corregimientos se debían a varias circunstancias. En primer lugar, a la mortalidad registrada a lo largo del siglo XVIII entre los corregidores titulares de las veintiuna varas de letras. Las cifras que nos ofrecen los datos biográficos disponibles establecen un índice de mortalidad del 9,1\%, es decir, de veinticuatro defunciones de corregidores en activo. Los corregimientos que resultaron más afectados fueron VélezMálaga, las Siete Villas de los Pedroches, Ubeda, Guadix y Alhama, con tres muertes en cada vara administrativa, mientras que, por el contrario, hubo ocho circunscripciones en las que no se produjo ningún deceso. Esta tasa es claramente inferior a la obtenida en los corregimientos militares (cerca del 30\%) y de capa y espada $(12,7 \%)$, y tiene su explicación en el método de provisión de estos cargos, donde en principio se observaba la designación de hombres en plenas facultades físicas y mentales, aunque en determinadas ocasiones fueran muy veteranos y acumularan muchos años de servicio. En segundo lugar, la corta presencia de algunos individuos en el cargo se explicó por el acenso a puestos de mayor responsabilidad y categoría administraliva. Esta circunstancia afectó a catorce corregidores, que vicron interrumpidas sus labores corregimentales por el traslado a empleos de cspecial relevancia, como las plazas de algunos de los tribunales de justicia de las chancillerías y audiencias, o varas de superior rango administrativo, como las alcaldías mayores de las grandes capitales corregimentales (Cádiz, Granada, Barcelona, Valencia). En tercer lugar, la sustitución de los corregidores antes de completar su trienio de ejercicio podía ocasionarse de manera voluntaria, a partir de las dimisiones, o forzosa, a través de la separación o destitución, y de las jubilaciones. Sin embargo, estas últimas circunstancias sólo repercutieron sobre cinco corregidores.

En el extremo opuesto, los casos puntuales en que se dilató en exceso el período de gobierno, se debieron a la concesión de prórrogas, a veces sustentadas en las solicitudes de toda o parte de la circunscripción interesada, y otras veces, mediante propuesta del Consejo de Castilla por conveniencias particulares a cada caso concreto. La situación más llamativa fue la protagonizada por el primer corregidor de las Siete Villas de los Pedroches. Francisco Díaz de Mendoza, designado en el año 1747 cuando fue recuperada para la Corona la jurisdicción real de esos territorios, hasta 
entonces en manos de la Casa de Alba, prolongó su mandato durante dieciseis años, hasta que se produjo su fallecimiento. Quizá, las especiales circunstancias derivadas de la necesidad de incorporar a la administración corregimental esos dominios señoriales, determinaron que la concesión de la vara se hiciera desde el principio por un período indefinido, en palabras del monarca "por el tiempo de mi voluntad"73.

A pesar de que la normativa vigente era contraria a la concesión de prórrogas, estas fueron más frecuentes de lo que cabía esperar, algunas manifestadas explícitamente, y otras sin confirmación como tales, en la prolongación de los ejercicios sin enviar sustitución de mando. Este tipo de situaciones reflejaban las contradicciones del sistema, sobre todo en aquellas ocasiones en que la ley era la razón argumentada para denegar ciertas peticiones, que en otras circunstancias se exceptuaba. No obstante, hubo circunscripciones donde no se otorgaron durante todo el siglo XVIII, como en Estepona, Jaén, Ubeda, Baza, Guadix, Mancha Real, Loja, Alhama, Campo de Gibraltar y Marbella.

La circunscripción administrativa más afectada respecto a la prorrogación de sus corregidores fue la de Bujalance, donde permanecieron más tiempo del prefijado cinco de sus letrados. Entre los beneficiados por esta concesión se encontraban Juan Posada de Celis (1748-1756), que se mantuvo por espacio de ocho años en el mando despúes de haber solicitado una prórroga u otro destino para poder mantenerse ${ }^{74}$; Francisco Moriones y Marco, que obtuvo una prórroga en su primer período de ejercicio (1756-1762) y repitió en el empleo tres años más tarde, hasta su renuncia en 176875; y Rufino Torralvo Agudo (1786-1800), el más veterano en el desempeño, ya que prolongó su gobierno por espacio de catorce años ${ }^{76}$. En el corregimiento de Cuatro Villas de la Hoya de Málaga sólo dos de sus titulares continuaron su gestión mediante prórroga: Leonardo José López Ballesteros (17201726) y Pedro Antonio Boldó (1755-1761), este último a partir de un decreto que expresaba: "cn atención al acierto y desinterés con que ha desempeñado su obligalción"77. En el resto de las demarcaciones andaluzas de letras apenas proliferó este fenómeno, si bien fueron varios los intentos de retrasar la marcha de determinados sujetos.

Debido a que el ejercicio del poder se concentraba cn las amplias funciones conferidas a la figura del corregidor, como delegado del rey en el municipio, y único responsable de su dirección, el balance que ofrecía el modo de gobierno podía resultar imprevisible, ya que dependía, en muchas oportunidades, del talante personalizado en cada uno de los sujetos designados. Por tanto, estas muestras de cierto carácter conservador, revelaban la tendencia de muchos pueblos hacia la conformidad, manifestada en retener a la autoridad que les parecía lavorable a sus intereses, frente a la prevención soterrada en la acogida de un desconocido, que no ofrecía ninguna garantía de mantener lo hasta entonces experimentado.

Aunque la reforma de la administración corregimental conducia a dotar de profesionalidad a las autoridades destinadas a su ejercicio gubernativo, sobre todo, por lo que respecta a los corregidores de letras, y a partir de las exigencias de formación 
requeridas a los pretendientes, creemos que su aplicación en Andalucía no fue estricta, completa, ni perfecta; no obstante, si pudo observarse una mayor preocupación en los ámbitos superiores de gobierno, que procuraba severas advertencias en cuanto se detectaba alguna disfunción administrativa.

Si bien, en líneas generales, el corregidor letrado tuvo una mayor aceptación en los municipios andaluces, en comparación a la recibida por militares y caballeros de capa y espada, como lo prueban las numerosas peticiones de cambio de rango corregimental desde distintas esferas, tampoco la labor de los magistrados estuvo exenta de críticas. No obstante, a diferencia de otros gobiernos, sí comenzó a verificarse un mayor seguimiento por parte del Consejo de Castilla, como órgano superior del gobierno central, que estrechó la vigilancia en los casos de mala gestión de los letrados, y procuró las debidas advertencias a los interesados. Según se desprende de las quejas dirigidas a las autoridades superiores competentes, los motivos que originaban situaciones de rechazo eran muy similares, aunque menos frecuentes, a los protagonizados por los corregidores militares y de capa y espada.

Varios corregidores de letras perdieron sus facultades físicas o mentales en el ejercicio del cargo político-administrativo. En esta línea de irregularidades se produjeron las circunstancias que obligaron a sustituir en 1781 al corregidor de Carmona, Francisco José de Béjar, y en 1799 al corregidor de Alhama, Vicente de Sedano. El primero de ellos, aunque era un letrado de dilatada experiencia y contaba con una evaluación inmejorable sobre su competencia de gobierno, accedió al mando de la circunscripción de Carmona con 88 años, en condiciones muy disminuidas, como podía confirmarse a través de las comunidades eclesiásticas, los síndicos y el fiscal de justicia de la ciudad de Carmona ${ }^{78}$. Finalmente, ante el fracaso de su mandato, el corregidor Francisco José de Béjar fue sustituido en 1782, y no volvió a obtener un puesto en la carrera, pues en la Cámara de Castilla se reseñaba en una nota su lamentable estado, calificado "decrépito por su avanzada edad"79. Las circunstancias concernientes al corregidor Vicente de Sedano eran similares pues su capacidad física se hallaba muy mermada y le impedía desenvolverse sin ayuda: "es anciano y enfermo, lo cual no le permite salir de su habitación" 80 . En la mayoría de las ocasiones, la actitud mostrada por los corregidores que habían llegado a estos límites era la de aferrarse al empleo a través de todo tipo dc artimañas administrativas, al tiempo que buscaban apoyos externos que les permiticran cubrir el expediente. El proceso de evaluación continua de las aptitudes y realizaciones prácticas a que se vieron sometidos, dió lugar a una interesante documentación en la que se reflejaba el propósito de racionalizar el ejercicio de la profesión. La vigilancia establecida para examinar el comportamiento de los corregidores nos proporciona la posibilidad de conocer los errores que, a juicio del Consejo de Castilla, se cometían con mayor frecuencia, así como los valores que se pretendía inculcar en estas autoridades, en búsqueda de la idoneidad que merecía la representación del cargo, y para el eficaz cumplimiento de sus deberes. Las reflexiones emitidas por el fiscal del Consejo, conde de Campomanes, a petición de la Cámara de Castilla, sobre el método de provecrse y servirse los corregimien- 
tos, recogido en el decreto de 29 de marzo de 1783, especificaban el tipo de males que aquejaban el talante de los corregidores, y la clase de dotes morales necesarias para asumir la responsabilidad de regentar las jurisdicciones reales:

"Hay vicios esencialmente opuestos a la Judicatura, cual es la codicia, la lascivia, el juego excesivo, la ociosidad, o desidia, la cortedad de talento, el genio bullicioso, y enredador, y otros defectos semejantes que manifiestan la perversión del ánimo, debiendo por el contrario el Juez ser modesto, desinteresado, templado en sus costumbres, aplicado al estudio y activo en el desempeño de sus obligaciones" 81

Con relación a los corregidores letrados que sirvieron en Andalucía, y en el período comprendido entre 1785 y 1788 , contamos con once prevenciones escritas acerca de los defectos encontrados en distintas épocas, de sus respectivas trayectorias politicas, en ocasiones instruidas antes de su acceso a una plaza andaluza, y en otras, después del ejercicio en esa región. Las tres recomendaciones expresadas con mayor frecuencia intentaban corregir las deficiencias de "interés", "actividad" y "genio", con que se conducían los sujetos en ese momento amonestados, e instaban a la represión de las mismas. En realidad, se trataba de paliar las imperfecciones del sistema administrativo que, debido a las amplias atribuciones conferidas al corregidor, facilitaban la extralimitación en el uso del cargo, a través de comportamientos prepotentes, de prácticas de cohecho, y de corruptelas en las funciones de gobierno.

Las circunstancias anómalas que fueron reprochadas al corregidor Pedro Bernardo de Sanchoyerto y Achúcarro, cuando fue designado en 1787 para la circunscripción de Vélez-Málaga, enjuiciaban su irregular ejercicio en el corregimiento de Cuenca. Al parecer, se le acusaba de haber sido demasiado proclive a engrosar artificialmente los beneficios del juzgado, provocando por este medio graves extorsiones al vecindario. Del mismo modo, se le tachaba de conducta negligente en el despacho de asuntos judiciales y en el abasto de pan ${ }^{82}$.

En el mismo año, Juan Antonio de Veinza y Abadía fue destinado al corregimiento de Lucena, con una severa advertencia sobre su anterior proceder en la vara de Arévalo, cuyas faltas se centraban en la codicia y el abandono de los asuntos gubernativos y policiales ${ }^{83}$.

En otras oportunidades, este tipo de recriminaciones oficiales revelaban las debilidades y extremos de carácter de algunos corregidores. Así, Andrés Vicente Carpintero y Esgueva, antes de hacer frente al mando de la circunscripción los Pedroches de Córdoba, fue tildado de temperamento violento, según el aviso que acompañaba a su nombramiento en la alcaldía mayor de Salamanca: "Vm. se exaspera con bastante facilidad, y prorrumpe en palabras poco correspondientes a la gravedad y decoro de su empleo" 84 . 
Por el contrario, a Juan Ramón Bravo y Uribe, corregidor de Baza, se le encomendaba que no se dejara llevar por la compasión y los afectos humanos, pues su calidad bondadosa y caritativa excedía la discreción de sus encargos en la administración de justicia, y entorpecía la consecución del bien general ${ }^{85}$.

Otro aspecto reflejado en estas advertencias, describía toda clase de abusos cometidos por la máxima autoridad en los municipios reales. El desempeño de Anastasio Francisco Aguayo y Ordoñez en Ciudad Real fue seriamente reprendido a causa de su deficiente conducta. Según constaba al Consejo, su ejercicio se había caracterizado por la desidia en el manejo de asuntos públicos, delegando la jurisdicción en sus tenientes, so pretexto de sus enfermedades. Pero al mismo tiempo, no reparó en enriquecerse a costa de apropiarse de los beneficios económicos que se generaban en el juzgado, imponiendo multas injustificadas ${ }^{86}$. De apropiación indebida de bienes públicos y ostentación de riqueza fue acusado el letrado Ramón Gabriel Moreno, tras su paso por el corregimiento de Chinchilla, bajo la amenaza del Consejo de retirarlo de la carrera administrativa ${ }^{87}$. No obstante, esta amonestación se repitió al conocerse su gestión en la alcaldía mayor de Cartagena, donde se hizo notorio el abuso desde el empleo de alcalde mayor y la imprudente conducta del cargo público:

"procedió con sumo interés en todos los asuntos y con particularidad en los de Justicia, habiendosele notado que a poco tiempo de ejercer aquella vara puso coche, compró plata labrada y contruyó una casa de bastante buque" 88

Esta forma de fiscalización revelaba la opinión de la administración central sobre la gravedad de las quejas recibidas, así como los resquicios procedimentales por los que se solía transgredir el funcionamiento del gobierno. A partir de estos aspectos es posible observar la importancia que adquiría, en algunas oportunidades, el perfil personal de estas autoridades investidas del poder absoluto en el municipio. Los resultados prácticos de gobierno a veces se circunscribían a factores sociológicos y a la idiosincrasia particular de cada individuo. Quizás por este motivo fucron relativamente frecuentes los escándalos provocados por los corregidores de todo rango, es decir, tanto los militares, como los de capa y espada y, aunque en menor grado, también los letrados, se vieron perjudicados a partir de la puesta en evidencia de sus debilidades. Por lo tanto, no es extraño que las prevenciones reales, como método de represión de los excesos, recogieran csta clase de muestras de comportamientos individuales. Asímismo, requiere atención cl círculo humano más próximo a los ámbitos de responsabilidad corregimental, por la calidad de relaciones establecidas entre las autoridades locales y el mando superior. La estrecha vinculación del corregidor letrado con los miembros del ayuntamiento, de cuya presidencia era titular, hacía necesaria la colaboración entre ambos poderes para la correcta aplicación de las atribuciones reales conferidas en favor del empleo otorgado. Las dificultades de entendimiento y de subordinación entre las élites municipales y el delegado real, fueron causa directa de muchas dislunciones en la imposición del gobierno territorial. 


\section{Aspectos sobre la promoción de los corregidores letrados}

El abanico de posibilidades abierto a la promoción de los letrados que ejercieron sus servicios en la administración territorial de Andalucía, fue más amplio de lo que en principio cabía esperar, sobre todo si tenemos en cuenta la modestia de algunas circunscripciones. Aunque los ascensos usuales en la carrera solían circunscribirse a la superación del rango establecido en la plaza que se dejaba vacante, también surgieron otras oportunidades que, en determinadas ocasiones, llevaron a los corregidores a culminar su trayectoria profesional en puestos de mayor prestigio en la magistratura. No obstante, la diversidad de categorías profesionales que se reflejaban en los curricula de los distintos letrados permitieron mostrar toda la gama de opciones ofrecidas por el sistema corregimental, así como el grado de movilidad laboral a partir de los méritos exhibidos. Esta variedad en la tipología biográfica de la clase gubernativa, se encontraba en correspondencia con la variopinta división administrativa de Andalucía, cuyas circunscripciones de letras coparon un vasto territorio de la Corona. Además, estos profesionales del derecho contaron con un magnífico complemento de colocación en las alcaldías mayores que, en algunas ocasiones, superaban en categoría, responsabilidad y prestigio político a buena parte de los corregimientos a ellos asignados. Por el contrario, otros letrados encontraron en Andalucía el término de su carrera, puesto que en eventuales casos registrados en esa región, las edades de acceso eran muy avanzadas, y en consecuencia fue muy alto el índice de corregidores que se retiraron, obtuvieron una jubilación, y también, en menor número, fallecieron en el ejercicio de estos cargos. Así, cerca del 35\% del total se vió obligado a abandonar por diversas causas el servicio en la administración territorial, hecho que alcanzó mayores proporciones en los destinos de modesto rango político, como Quesada y los Pedroches, así como en los corregimientos de mayor antigüedad histórica, como Cuatro Villas de la Hoya de Málaga y Vélez-Málaga.

Aquellos que prosiguieron en la misma línea de empleo, continuaron preferentemente en corregimientos y alcaldías mayores de Andalucía. Los destinos más habituales, a lo largo de todo el siglo XVIII, condujeron a los letrados cumplidos a vecinos corregimientos de letras como Cuatro Villas de la Hoya de Málaga, Lucena, Ubeda o Carmona, en mayor proporción que los restantes, así como a importantes alcaldías mayores de circunscripciones político-militares, como Cádiz y Málaga, y de capa y espada, como Jerez de la Frontera, Ronda, Córdoba y Ecija.

Dentro de la carrera burocrática seguía en importancia por el número de promociones comprobadas desde esta región, las colocaciones situadas en varas de ambas Castillas y del reino de Murcia, destacando el frecuente traslado a esta última región, por razones lógicas de proximidad geográfica. Sin embargo, fue mucho menor la movilidad administrativa hacia varas de la Corona de Aragón $(2,9 \%)$ y muy poco significativa en destinos del norte de España y Extremadura.

En orden a la entidad de responsabilidades políticas encomendadas a los letrados de reconocida experiencia y antigüedad, las dos varas de la alcaldía mayor de Cádiz constituían unos de los destinos más apreciados para culminar una carrera de 
letras. Con referencia a su categoría, a finales del siglo XVIII era la máxima, es decir, la tercera clase, y su valor económico en salarios y emolumentos superaba en ambos casos los 60.000 reales $^{89}$, bastante por encima de las restantes circunscripciones. Además, la posesión de estos cargos gaditanos solía traer consigo la posibilidad de ganar tratamiento honorífico en tribunales de la magistratura ${ }^{90}$. También era de considerable importancia la vara de Málaga, cuyo valor se situaba en los 42.240 reales ${ }^{91}$.

Del mismo modo, fuera de Andalucía era muy apreciado el destino en el corregimiento de Lorca, que rondaba las ganancias de 44.000 reales, así como la vara más antigua de teniente de corregidor de Madrid, que se encontraba en los 31.700 reales 92 . Con respecto a las circunscripciones situadas en la Corona de Aragón, las varas de Valencia destacaban como un eficaz trampolín para acceder a otros puestos de la magistratura, y la del corregimiento político-militar de Alicante solía ser un paso previo a posibles ascensos de mayor relive, en plazas de superior categoría.

Otra forma de ascenso desde la carrera de varas consistía en el traslado a los corregimientos de Guipúzcoa y Vizcaya, que por sus especiales características habían estado encomendados, tradicionalmente, a oidores de la Chancillería de Valladolid y del Consejo de Navarra ${ }^{93}$. Esta tendencia normativa fue modificada, pues entre las propuestas sugeridas por el fiscal Campomanes con motivo de la nueva instrucción de corregidores del 29 de marzo de 1783 , se contempló la posibilidad de incluir a los corregidores y alcaldes mayores que hubiesen completado los ascensos en el escalafón, y que poseían méritos especiales ${ }^{94}$. El tránsito hacia csos puestos constituyó, por tanto, una forma excepcional de premiar determinadas carreras de letrados. En este aspecto, en tres ocasiones se dió la pertinente circunstancia de promoción a dichas circunscripciones vascas. Así, Bernardo de Luque y Muñana culminó su trayectoria burocráctica en 1784 al frente del corregimiento de Guipúzcoa, despues de servir el corregimiento de Bujalance y una de las varas de Cádiz ${ }^{95}$. Similares antecedentes presentaba el curriculum de Juan Ortiz y Azorín, corregidor de Guadix en 1776, pasó después por la alcaldía mayor de Jerez de la Frontera (1780) y cl corregimiento de Alcaraz (1784), donde sólo permaneció un año debido a su promoción a la primera vara de Cádiz, con honores de alcalde del crimen de la Chancillería de Granada. Finalmente, alcanzó en 1789 la dirección del corregimiento de Vizcaya, tras haber acumulado 46 años de servicios en la administración territorial ${ }^{96}$. Otra muestra, csta vez desde el desempeño del corregimiento de tercera clase de Lucena, la ofrece José Ronger cuando fue designado para la circunscripción de la provincia de Guipúzcoa en el año $1787^{97}$.

No obstante, también entre las biografías de los letrados que sirvieron en Andalucía se dispuso el trámite tradicional establecido para el clesempeño de esos corregimientos superiores. El recorrido funcionarial de Gaspar Delgado LLanos reflejó los pasos que fueron habituales durante casi todo el siglo XVIII para alcanzar ese ascenso, y en relación a su mérito constituyó uno de los letrados que con mayor brillantez cumplimentó su trayectoria en la profesión de la magistratura, puesto que en el año 1768 recibió el ascenso a una plaza de alcalde del crimen de la Chancillería 
de Valladolid ${ }^{98}$, posteriormente, el cargo de oidor del mismo tribunal ${ }^{99}$, y en el año 1781 falleció en el ejercicio del corregimiento de Guipúzcoa ${ }^{100}$, en el que se había mantenido desde 1778.

A partir de la reforma del entramado corregimental, los dilatados años de servicio y los méritos adquiridos durante el ejercicio del gobierno territorial podían ser recompensados mediante el ascenso a plazas de la magistratura en Audiencias y Chancillerías ${ }^{101}$. La aproximación más generalizada a estas plazas togadas, comenzó con la concesión de honores, que de forma habitual se otorgaban conjuntamente a nuevos nombramientos en varas representativas. En la nómina de letrados que nos ocupa, recibieron honores de alcalde del crimen más de una decena de corregidores.

Además de este tipo de privilegios honoríficos, también hubo un discreto número de corregidores y alcaldes mayores que obtuvieron en propiedad plazas en los tribunales superiores. Los empleos de alcaldes de hijosdalgo y alcaldes del crimen fueron la culminación de la carrera de otros diez letrados, en las Chancillerías de Granada y de Valladolid, así como en las Audiencias de Sevilla, Valencia, Aragón, Galicia, Extremadura y Cataluña. Pero sin duda, los ascensos más significativos fueron protagonizados por los corregidores letrados que asumieron plazas de oidores, constituyendo una élite profesional respecto al resto de sus compañeros en la carrera, por la superación de la usual trayectoria política ${ }^{102}$. Agustín Ramírez de Losada se hallaba en el ejercicio de Vélez-Málaga desde 1718, y en 1722 ya fue propuesto para una plaza de juez de la Audiencia de Canarias, que finalmente no consiguió ${ }^{103}$. No obstante, el año 1725 le fue conferida una plaza de alcalde del crimen de la Audiencia de Cataluña, y en los años 1729 y 1733 fue consultado para el cargo de oidor del mismo tribunal, que por fin obtuvo en $1738^{104}$. Gonzalo de Rioja y Valladares desempeñó el corregimiento de Vélez-Málaga entre 1745 y 1750. Despues fue promocionado desde la alcaldía mayor de Murcia (17501755) al empleo de alcalde del crimen de la Audiencia de Aragón ${ }^{105}$, gestión desde la que recibió en 1762 el ascenso a una plaza de oidor de la Chancillería de Granada ${ }^{106}$. Para finalizar, coronó su trayectoria con la obstención, en el año 1771, de honores del Consejo de Ordenes ${ }^{107}$. El corregidor Francisco Ruíz Albornoz, en la vara de Vélez-Málaga durante el período 1760-1763, asumío en 1768 el corregimiento de Lorca, fue nombrado en 1771 alcalde de hijosdalgo de la Chancillería de Valladolid. Prosiguió su ascenso en 1775 en la vara de alcalde del crimen, y en 1781 en la plaza de oidor, puesto en el que se jubiló en 1790108. Tras su paso en 1776 por la gestión del modesto corregimiento de Mancha Real, José de Moya fue promovido, y de cierta forma recompensado en 1779 , con una plaza de oidor de la Audiencia de Nueva Galicia. Sin embargo, con anterioridad había desempeñado varas de mayor relevancia administrativa como la alcalúía mayor de Cartagena (1768-1772) y la alcaldía mayor de Barcelona (1773-1776)109. José Díaz Huerta, corregidor de Ubeda entre los años 1772 y 1775, recibió el nombramiento de alcalde y oidor de la Audiencia de Sevilla ${ }^{110}$. En los inicios de su carrera Pedro Nicolás del Valle ejerció el corregimiento de Estepona (1773-1777). En 1782 fue nombra- 
do alcalde mayor de Burgos ${ }^{111}$, y posteriormente ascendió a la plaza de Auditor del ejército de Navarra y Guipúzcoa. La calidad de sus méritos le proporcionaron la obtención, años después, de una plaza de oidor de la Audiencia de Galicia ${ }^{112}$, y en 1794 alcanzó el privilegio de recibir honores de alcalde de Casa y Corte ${ }^{113}$

\section{NOTAS}

1. Como en el caso extremo de la circunscripción de Quesada: "siendo esta vara de las menos apetecibles de la carrera, son los pretendientes de ínfima clase, pero que todos tienen a su favor la presunción por la consulta de la Cámara.”, Vid. A.H.N., Consejos, Leg. 13.284: Informe de D. Rodrigo de Cepeda, 5 de noviembre de 1725.

2. A.H.N., Consejos, Leg. 13.623: La Cámara de Castilla, 2 de febrero de 1747.

3. A.G.S., Gracia y Justicia, Leg. 158: El marqués de Squilace, 29 de noviembre de 1762.

4. A.G.S., Gracia y Justicia, Leg. 156: Decreto, 17 de enero de 1760.

5. A.H.N., Consejos, Leg. 13.614: Manuel de Roda, 11 de abril de 1767.

6. GIMÉNEZ LÓPEZ, E.: Militares en Valencia (1707-1808), Alicante, Instituto de Cultura Juan Gil-Albert, Diputación de Alicante, 1990. pp. 52-53.

7. Las primeras nociones de gobierno de muchos de los corregidores nombrados para las nuevas circunscripciones de letras, provenían del desempeño en diversas alcaldías mayores, tanto de señorío como de realengo.

8. "... en lo demás de capa y espada que la Cámara considere indotados y conveniente se reduzcan a corregimientos de letras me lo consultará exponiendo las circunstancias y calidades de cada uno de ellos". A.H.N., Consejos, Leg. 13.601: Consulta, 17 de agosto de 1767.

9. En el mismo año se transformaron en corregimientos de letras el de Carrion y cl de Avila, mientras que en 1769 lo hicieron Medina del Campo, Sahagún y Logroño. A.H.N., Consejos, Leg. 13.612: La Cámara, 19 de enero y 20 de marzo de 1768.

10. A.H.N., Consejos, Leg. 13.595: 14 de julio y 8 de octubre de 1768; y Leg. 13.639: 8 do octubre de 1768.

11. A.N.N., Consejos, Leg.13.618: La Cámara, 26 de junio de 1769 y 14 de julio de 1769.

12. A.H.N., Consejos, Leg. 13.595: Consulta acordada, 7 de septiembre de 1768 y 5 de abril de 1769; y Leg. 13.608: 12 de abril de 1769.

13. A.H.N., Consejos, Leg. 13.589: Consulta de la Cámara, 7 de marzo de 1772; y Leg. 13.615: 13 de mayo de 1772 .

14. A.H.N., Consejos, Leg. 13.616: Memorial de la ciudad de Marbella, 20 de noviembre de 1773; La Cámara, 14 de julio de 1776; y Leg. 13.625: La ciudad de Ronda, 11 de julio de 1775.

15. Otros corregimientos de letras de reciente creación fueron: Albacete, Atienza (scgregado de Molina) y Calahorra y Alfaro (segregados ambos de Logroño). 
16. El gobierno político-militar de Almería en el siglo XVII estaba constituído como corregimiento de letras.

17. A.H.N., Consejos, Leg. 13.606: Consulta del Consejo, 9 de junio y 11 de noviembre de 1769.

18. A.G.S., Gracia y Justicia, Leg. 152: Informe de Francisco del Rallo y Calderón, 27 de enero de 1751.

19. CADENAS Y VICENT, V.: Extracto de los expedientes de la Orden de Carlos III (177I1847), Madrid, Instituto Salazar y Castro (CSIC), Tomo III (1981), pp. 136-137.

20. A.G.S., Gracia y Justicia, Leg. 151: Informe de Cristobal de Monsoriu, 9 de julio de 1750.

21. A.G.S., Gracia y Justicia, Leg. 156: Informe de Tomás Pinto Miguel, 13 de marzo de 1758.

22. CADENAS Y VICENT, V.: Extracto de los expedientes..., Op. Cit., Tomo XII, pp. 12-13.

23. A.G.S., Gracia y Justicia, Leg. 163: Corregimiento de Málaga, 19 de mayo de 1781.

24. CADENAS Y VICENT, V.: Extracto de los expedientes..., Op. Cit., Tomo IV, pp. 78-80.

25. A.G.S., Gracia y Justicia, Leg. 162: Alcaldía mayor de Jerez de la Frontera, 21 de octubre de 1780 .

26. A.G.S., Gracia y Justicia, Leg. 163: Corregimiento de Jaén, 27 de noviembre de 1782.

27. A.G.S., Gracia y Justicia, Leg. 158: Alcaldía mayor de Ecija, 26 de noviembre de 1763.

28. B.O.E., Gaceta de Madrid: 25 de septiembre de 1764.

29. A.G.S., Gracia y Justicia, Leg. 163: Alcaldía mayor de las Alpujarras, 14 de noviembre de 1781 .

30. A.H.N., Consejos, Leg. 13.266: Relación de méritos y servicios de José Teodosio Delgado y Mentera, año 1777.

31. A.G.S., Gracia y Justicia, Leg. 142: Corregimiento de Orense, 24 de febrero de 1732. Vid. BURKHOLDER, M.: De la Impotencia a la autoridad: La Corona española y las Audiencias en América, 1687-1808, Méjico: Fondo de Cultura Económica, 1984, 478 p.

32. B.O.E., Gacela de Madrid: 19 de diciembre de 1769; y PÉREZ SAMPER, Ma A.: "Los ministros de la Chancillería de Granada", Actas Il Coloquios de Historia de Andalucía, Córdoba, Tomo II, 1983, p. 151.

33. GIMÉNEZ LÓPEZ, E.: Militares en Valencia..., Op. Cit., p. 170; y PÉREZ SAMPER, M* A.: "Los ministros de la Chancillería...', Op. Cit., p. 140.

34. "sin que en medio de no haberse hecho el matrimonio a gusto de los parientes de ella, se le pudiese notar culpa en su conducta". Vid., A.G.S., Gracia y Justicia, Leg. 153: Alcaldía mayor de Marbella, 5 de octubre de 1754.

35. A.G.S., Gracia y Justicia, Leg. 153: Alcaldía mayor de Fiñana, 29 de abril de 1754.

36. "A pesar de la fidelidad mostrada por Castilla para con la nueva dinastía, y a pesar también de que sus leyes y forma de gobierno hubiesen servido como modelo explícito para la Nueva Planta, su entramado institucional no quedó al margen por completo de las novedades introducidas por Felipe V.", Cfr. FERNÁNDEZ ALBADALEJO, P.: "La monarquía", en Actas del Congreso Internacional sobre "Carlos III y la llustración", Tomo I, El Rey y la Monarquía, p. 29.

37. Sobre este particular, el camarista Juan Millán expresaba: "así por considerarle merecedor de el, como para que este premio sirva de estímulo a los demás"; mientras que Melchor 
de Macanaz corroboraba: "que lo ha ejecutado con grande industria, y que para animar a otros, conviene alentar con el premio a los que le merecen como este". Vid., A.G.S., Gracia y Justicia, Leg. 133: Corregimiento de Bujalance, 26 de julio de 1714.

38. A.G.S., Gracia y Justicia, Leg. 133: Corregimiento de Cuatro Villas de la Hoya de Málaga, 15 y 22 de febrero de $1716 ;$ y 8 y 13 de agosto de 1716.

39. Se le tildaba de carácter "intrépido". Vid., A.G.S., Gracia y Justicia, Leg. 133: Corregimiento de Bayona, año 1716.

40. A.H.N., Consejos, Leg. 13.590: Memorial de D. Antonio Cristobal Cornejo, 14 de septiembre de 1708.

41. A.H.N., Consejos, Leg. 13.590: Corregimiento de Andujar, 12 de junio de 1709.

42. A.H.N., Consejos, Leg. 13.602: Corregimiento de Cuatro Villas de la Hoya de Málaga, 14 de abril de 1707.

43. A.G.S., Cracia y Justicia, Leg. 134: Corregimiento de Bujalance, 13 y 20 de marzo de 1718.

44. Los corregimientos militares que permanecieron como tales hasta finales del siglo XVIII fueron Cádiz, Sanlúcar de Barrameda, Puerto de Santa María, Málaga, Motril y Almería, mientras que continuaron siendo de capa y espada las circunscripciones de Granada, Córdoba, Ronda, Jerez de la Frontera, Ecija y Antequera.

45. Los catalanes y los navarros alcanzaban el 5,8\%, respectivamente; los extremeños el 4,3\%; los aragoneses el 3,6\%; los riojanos el $2,9 \%$; los vascos y los valencianos el $2 \%$, respectivamente; los gallegos, asturianos y cántabros el 1,5\%; y los canarios y mallorquines el $0,7 \%$, respectivamente.

46. OLAECHEA, R: "El anticolegialismo del gobierno de Carlos III", Cuadernos de Investigación, Geografia e Historia, Publicaciones del Colegio Universitario de Logroño, Tomo III (1976), pp. 61-62.

47. MOLAS RIBALTA, P.: "Los magistrados de Carlos III. El caso de Valencia", en Actas del Congreso Internacional sobre "Carlos III y la llustración", Tomo I, El Rey y la Monarquía, p. 421.

48. "Por su valor relativo, el grado de doctor no era codiciado por los letrados, y sólo un número reducido de ellos lo poseía". Cfr. GIMÉNEZ LÓPEZ, E.: Militares en Valencia..., Op. Cit., p. 171.

49. Pedro Antonio Boldó Garcia se doctoró en derecho por la Universidad de Valencia; Juan Antonio Pueyo y Sansón por la de Huesca; Epifanio Fortuny por la de Cervera; José Díaz Huerta por la de Alcalá de Henares; mientras ignoramos la procedencia universitaria del grado obtenido por los también doctores Pedro Moscoso y Figueroa, José Ignacio LLorens y Francisco Javier Lozano y Avellán.

50. "Advirtamos que el simple hecho de haber opositado era ya un punto positivo que se valoraba como mérito en los aspirantes y candidatos a obtener plazas togadas.", Cfr. PÉREZ SAMPER, Ma. A.: "Los ministros de la Chancillería..., Op. Cit., p. 135.

51. "La cátedra, sustituciones y en general toda experiencia universitaria, fue considerada más importante que la misma licenciatura, convirtiendose en un primer paso para ocupar los cargos en la administración de la Iglesia y del Estadio". Cfr. SANTA CRUZ, M "T. y VILA, E.: "Los Colegiales mayores de San Bartolomé: 1660-1768", Pedralbes. Revista d'historia Moderna, No 4 (1984), p. 382. 
52. A.G.S., Gracia y Justicia, Leg. 162: Corregimiento de Andujar, 17 de junio de 1778.

53. "que su lucimiento y explendor en la cátedra ha tenido un gran crédito como también le había adquirido en las oposiciones que hizo a Prebendas en las principales Iglesias de España.", Vid., A.G.S., Gracia y Justicia, Leg. 159: Corregimiento de Baeza, 22 de agosto de 1768.

54. A.G.S., Gracia y Justicia, Leg. 142: Relación de servicios de Ventura Antonio Chacón y Mújica, año 1732.

55. Entre los mencionados aparecían Cistobal de Espinosa, Juan Manuel Barrionuevo, Bruno Burruezo y Agustín Gutierrez. Sobre las circunstancias de estos magistrados del tribunal granadino, Vid. PÉREZ SAMPER, $\mathrm{M}^{\mathrm{a}}$ A.: "Los ministros de la Chancillería de Granada...", Op. Cit., pp.144-152.

56. RISCO, A.: La Real Academia de Santa Barbara de Madrid (1730-1808), Naissance et formation d'une èlite dans l'Espagne du XVIIlème siécle, Toulouse, 1979, 2 vols.

57. ÁLVAREZ DE MORALES, A.: "La crisis del Reformismo en Campomanes", Revista de Historia Moderna. Anales de la Universidad de Alicante, n 8-9 (1988-1990), pp. 185 195.

58. Según señala el profesor Molas Ribalta, contituía el "Colegio mayor de los Manteistas', destinado a la formación de corregidores ilustrados entre los abogados de la Corte", Cfr. MOLAS RIBALTA, P.: "Los colegiales mayores en la Audiencia de Valencia (siglos XVII-XVIII)", Pedralbes. Revista d'historia Moderna, no 1 (1981), p. 67.

59. Los letrados que acreditaron el ejercicio como abogados de una población fueron: Juan Manuel de Fontanilla, en Avila; José Teodosio Delgado y Mentera, en Guadix; Antonio Giménez Bravo, en Ciudad Real; Antonio José Cortes, en la villa de Bienvenida, al tiempo que indicaba el nombramiento de diputado del común de Villanueva de la Serena; Luis Tassara e Hilson, en Sanlúcar de Barrameda, donde también fue elegido diputado del Común; y Pablo Antonio Collado, en Baza, y con el cargo añadido de asesor del Regimiento de Milicias de esa ciudad.

60. Los abogados que mantuvieron un despacho propio fueron:

Ramón Patricio Moreno

Diego José Carrillo de Rueda

Juan Posada de Celis

Pablo Bernardo de Sanchoyerto

Francisco Serrano de Frías

Dionisio $\mathrm{M}^{\mathrm{a}}$ Montalvo

Antonio Anguiozar y Velasco

Antonio Giménez Bravo

Gaspar de Aranda y Villegas

Francisco Agorreta y Nuño

José Manuel Picado

Juan José de Cañaveras

Antonio José Cortes

Martín Alonso de Quesada

Miguel la Torre González Sardina

José Fernández Quevedo

en Madrid
en Sigüenza
en Sevilla
en Valladolid
en Madrid y Toledo
en Granada
en Madrid
en Ciudad Real
en Granada
en Navarra
en Roa
en Huete
en Villanueva de la Serena
en Linares
en Canarias
en Murcia


61. A.G.S., Gracia y Justicia, Leg. 147: Relación de méritos de Juan Moreno Vallejo, 30 de abril de 1745 .

62. A.G.S., Gracia y Justicia, Leg. 155: Alcaldía mayor de Motilla del Palancar, 16 de mayo de 1757.

63. A.G.S., Gracia y Justicia, Leg. 151: Corregimiento de Cuatro Villas de la Hoya de Málaga, 9 de julio de 1750.

64. Como indica el profesor Giménez López: "Los resultados de su gestión daban la medida del letrado por la equivalencia del objetivo último de ambas funciones: la sujeción del territorio al orden y a la autoridad legítima, reproduciendo las atribuciones del corregidor a menor escala." Cfr. GIMÉNEZ LÓPEZ, E.: Militares en Valencia..., Op. Cit., p. 178.

65. A.G.S., Gracia y Justicia, Leg. 160: Alcaldía mayor de Sanlúcar de Barrameda, 15 de enero de 1772.

66. A.G.S., Gracia y Justicia, Leg. 161: La Cámara, 22 de mayo de 1775.

67. El patrimonio territorial del marquesado de los Vélez tenía su cabeza de señorío en Vélez-Blanco. A.G.S., Gracia y Justicia, Leg. 157: Relación de Méritos de Alonso López Camacho, 11 de junio de 1765.

68. A.G.S., Gracia y Justicia, Leg. 164: Relación de méritos del licenciado Antonio Francisco Freire de Cora, 7 de junio de 1785.

69. GONZÁLEZ ALONSO, B.: Sobre el Estado y la Administración de la Corona de Castilla en el Antiguo Régimen, Madrid, 1981, Siglo XXI, pp. 143-176.

70. GONZÁLEZ ALONSO, B.: El corregidor castellano..., Op. Cit., p. 271.

71. GIMÉNEZ LÓPEZ, E.: "El debate civilismo-militarismo y el Régimen de NUeva Planta en Ia España del siglo XVIII", en Cuadernos de Historia Moderna. Universidad Complutense, 15 (1994), pp. 39-73.

72. GIMÉNEZ LÓPEZ, E.: "Campomanes y la reforma de la Administración territorial", en Actas del Coloquio Intemacional Carlos III y su siglo, Madrid, 1990, Tomo I, pp. 941962.

73. A.H.N., Consejos, Leg. 13.623: Real Orden, 2 de febrero de 1747.

74. A.G.S., Gracia y Justicia, Leg. 152: Memorial de Juan Posada de Celis, año 1752; y A.H.N., Consejos, Leg. 13.596: La Cámara, 24 de febrero de 1752.

75. A.H.N., Consejos, Leg. 13.596: Corrregimiento de Bujalance, 19 de junio de 1758; y A.G.S., Gracia y Justicia, Leg. 159: Corregimiento de Bujalance, 3 de febrero de 1768.

76. A.H.N., Consejos, Leg. 13.596: Corregimiento de Bujalance, 7 de junio de 1797.

77. A.H.N., Consejos, Leg. 13.602: Real Decreto, 4 de mayo de 1758.

78. A.H.N., Consejos, Leg. 13.601: Memorial de Juan de Villalva, vecino de Carmona, 2 de mayo de 1781.

79. A.H.N., Consejos, Libro 714: año 1783, fols. 39 y 40.

80. A.H.N., Consejos, Leg. 13.589: La Cámara al Sr. Presidente de la Chancillería de Granada, 4 de septiembre de 1799.

81. A.H.N., Consejos, Libro 714: 5 de mayo de 1783, fol. 90.

82. A.G.S., Gracia y Justicia, Leg. 164: A D. Pedro Bernardo de Sanchoyerto, San Ildefonso, 1 de septiembre de 1787. 
83. A.G.S., Gracia y Justicia, Leg. 164: A D. Juan Antonio de Veinza y Abadía, San Ildefonso, 1 de septiembre de 1787.

84. A.G.S., Gracia y Itusticia, Leg. 163: A D. Andrés Vicente Carpintero y Esgueva, San Ildefonso, 20 de enero de 1786.

85. A.G.S., Gracia y Justicia, Leg. 163: A. D. Juan Ramón Bravo y Uribe, San Ildefonso, 6 de mayo de 1785 .

86. A.G.S., Gracia y Justicia, Leg. 163: A. D. Anastasio Francisco Aguayo y Ordoñez, San Ildefonso, 29 de septiembre de 1786.

87. A.G.S., Gracia y Justicia, Leg. 163: Corregimiento de Alcaraz, 15 de marzo de 1786.

88. A.G.S., Gracia y Justicia, Leg. 163: A D. Ramón Gabriel Moreno, San Ildefonso, 29 de septiembre de 1786.

89. Lá vara más antigua de Cádiz sumaba 66.457 reales anuales en sueldo y consignaciones fijas, mientras que la más moderna alcanzaba los 60.957 reales. Vid., A.H.N., Consejos, Libro 714: fol. 129.

90. Como muestra, Juan Posada de Celis, cuando fue nombrado en 1756 para la recién creada segunda vara de Cádiz, adquirió honores de oidor de la Audiencia de Sevilla, y culminó su carrera en la vecina alcaldía mayor de Málaga. Vid., A.H.N, Consejos, Leg. 13.261: Vara segunda de Cádiz, 8 de enero de 1756; y Leg. 13.271: Alcaldía mayor de Málaga, 11 de septiembre de 1761 .

91. A.H.N., Consejos, Libro 714: Fol. 130.

92. A.H.N., Consejos, Libro 714: Fol. 130.

93. Así señala el profesor Gómez-Rivero la dimensión de estas plazas: "En cierto modo, el empleo de corregidor de esos territorios venía a ser una comisión que se otorgaba a dicho oidor, que continuaba como tal además de corregidor. Su plaza de oidor no se cubría, pienso, porque la concesión de uno de esos corregimientos no suponía un ascenso, aunque sí méritos profesionales estimables con vistas a una futura promoción." Cfr. GÓMEZ-RIVERO, R.: Las competencias del Ministerio de Justicia..., Op. Cit., pp. 137139.

94. A.H.N., Consejos, Libro 714: 5 de mayo de 1783, fols. 82-83.

95. Fue designado para Cádiz en el año 1774, y prorrogado en la misma vara en 1781, por recomendación expresa del conde O'Reylli, gobernador político-militar de esa circunscripción. Vid. A.H.N., Consejos, Leg. 13.261: La Cámara, 8 de agosto de 1774; y A.G.S., Gracia y Justicia, Leg. 163: Corregimiento de Guipúzcoa, 10 de junio de 1786.

96. A.G.S., Gracia y Justicia, Leg. 162: Alcaldía mayor de Jerez de la Frontera, 21 de oculbre de 1780; Leg. 163: Primera vara de alcalde mayor de Cádiz, 15 de marzo de 1785; y A.H.N., Consejos, Leg. 13.261: Corregimiento de Vizcaya, 22 de septiembre de 1789.

97. A.H.N., Consejos, Leg. 13.613: Corregimiento de la provincia de Guipúzcoa, 25 de julio de 1787.

98. A.G.S., Gracia y Jusicia, Leg. 159: Plaza de Alcalde del Crimen de la Chancillería de Valladolid, 3 de febrero de 1768.

99. GÓMEZ-RIVERO, R.: Las Competencias del Ministerio de Justicia..., Op. Cit., p. 362.

100. A.G.S., Gracia y Justicia, Leg. 163: Corregimiento de Guipúzcoa, 17 de enero de 1781.

101. A.H.N., Consejos, Libro 714: fol. 82. 
102. Según el profesor Gómez-Rivero, "son la excepción que confirma la regla de que una vez dentro de la carrera de Varas y Corregimientos es prácticamente imposible sustraerse de ella.", Cfr. GÓMEZ-RIVERO, R.: Las competencias del Ministerio de Justicia..., Op. Cit., p. 137.

103. A.G.S., Gracia y Justicia, Leg. 136: Audiencia de Canarias, año 1722.

104. A.G.S., Gracia y Justicia, Leg. 145: Ministros de lo civil de la Audiencia de Cataluña, 1 de octubre de 1737; y B.O.E., Gaceta de Madrid: 11 de marzo de 1738.

105. A.G.S., Gracia y Justicia, Leg. 154: Plaza de Alcalde del Crimen de la Audiencia de Aragón, 2 de abril de 1755.

106. A.G.S., Gracia y Justicia, Leg. 158: Plaza de oidor de la Chancillería de Granada, 27 de noviembre de 1762 .

107. B.O.E., Gaceta de Madrid: 13 de agosto de 1771.

108. A.G.S., Gracia y Justicia, Leg. 159: Corregimiento de Lorca, 9 de enero de 1768; Leg. 160: Primera Tenencia de Sevilla, 26 de febrero de 1772; y MOLAS RIBALTA, P.: “Los ministros de la Chancillería..., Op. Cit., pp. 251 y 254.

109. A.G.S., Gracia y Justicia, Leg. 159: Alcaldía mayor de Cartagena, 28 de septiembre de 1768; Leg. 161: Alcaldía de Barcelona, 19 de enero de 1773; y Leg. 162: Plaza de oidor de la Audiencia de Nueva Galicia en Nueva España, 24 de marzo de 1779.

110. GÓMEZ-RIVERO, R.: Las competencias del Ministerio de Justicia..., Op. Cit., p. 363.

111. A.G.S., Gracia y Justicia, Leg. 163: Alcaldía mayor de Burgos, 24 de abril de 1782.

112. B.O.E., Gaceta de Madrid: 3 de junio de 1794.

113. Sobre la categoría de ese destino, Gómez-Rivero señala: "La plaza de alcalde de Casa y Corte supone un ascenso para los oidores y alcaldes de las Chancillerías, Audiencias y Consejo Real de Navarra -también por los fiscales de estos tribunales- y, además, el desempeño de una Alcaldía de este tipo era casi vía obligada antes de ocupar una plaza del Consejo de Hacienda y del de Ordenes." Cfr. GÓMEZ-RIVERO, R.: Las competencias del Ministerio de Justicia..., Op. Cit., p. 219. 